\title{
Prevalence of Catheter-related Bloodstream Infection and Distribution of Multidrug Resistance Microorganisms among the Hospitalized Patients
}

\author{
Oltiana Petri ${ }^{1,2,3 *}$, Klotilda Vrenjo ${ }^{2}$, Alda Angjeli $^{1}$, Erjona Abazaj ${ }^{4}{ }^{\mathbb{D}}$, Blerta Kika ${ }^{4}$, Andi Koraqi $^{3}$, Albana Daka $^{1}$ \\ ${ }^{1}$ Department of Microbiology, American Hospital, Tirana, Albania; ${ }^{2}$ Department of Education and Health, Sports University, \\ Tirana, Albania; ${ }^{3}$ Department of Microbiology, University of Medicine, Tirana, Albania; ${ }^{4}$ National References Laboratory, \\ Institute of Public Health, Tirana, Albania
}

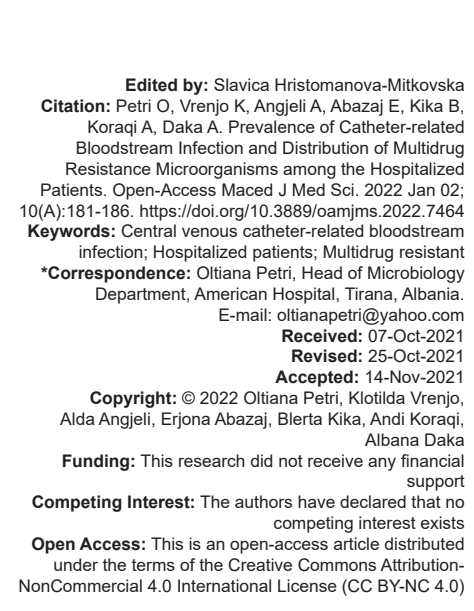

Introduction

Nowadays, the medical science has made great progress in perfecting of case management treatment protocols as well as in medical equipment and diagnostic methods. Modernization of medical sciences is increasingly providing and implementing a large number of medical devices which have increased the quality of life of the patient, through the increasing efficiency of intravenous administration of medical drugs and fluids as well as helping to improve the results of conditions of certain medical [1], [2], [3]. The use of venous catheters (VCs) has become quite common in medical practices, where in most cases, they are considered quite appropriate in many of the lifesaving situations [4]. However, on the other hand, the implementation of those medical devices, especially VC in the patient's body, in addition to the benefits it brings to their good performance, shows some complications such as vascular, cardiac, and pulmonary complications, complications during their placement.

Last but not least are the various infections that patients can get when manipulating VCs. Marcos et al. mentioned in their paper that bloodstream infections are a significant cause of morbidity and increased mortality in health-care facilities as a consequence of central VC-related bloodstream infection (CRBSI) [5]. They attributed to an increased length of stay and increased costs [6]. The use of a VC plays a significant risk factor for circulatory infections [7]. The range of infections encountered in 5 million catheters installed within a year in the United States of America (USA) ranges from 250,000 to 400,000 cases. Bacteria, molds, and yeasts are the most common infections in these catheters installed [3], [8], [9].

Seeing the major problems related to infections encountered in the installation of central VCs, we have 
undertaken this study to evaluate the prevalence, risk factors, and outcomes of blood infections associated with central VC, in patients hospitalized at the University Hospital Center "Mother Teresa" (UHCMTH) and American Hospital, Tirana, over a period of 3 years from January 2016 to December 2018.

\section{Methods}

A retrospective study was performed for hospitalized cases at the UHCMTH and American Hospitals $(\mathrm{AH})$ who have been treated for infections caused by VC during the period 2016-2018. In this paper, we have included 170 suspected cases for CRBSI, $126(74.1 \%)$ cases were involved by the microbiological laboratory of UHC, while 44 (25.9\%) cases were involved by the microbiological laboratory of the $\mathrm{AH}$. Inclusion criteria were all patients (women and men) hospitalized at the UHCMTH and American Hospital during the period 2016-2018, for various problems, and after the use of VCs, they are suspected for CRBSI infection. All individuals aged $18 \pm 75$ years, who have been monitored for VC infections. Patients suspected and tested in respective microbiological laboratories (UHCMT and $\mathrm{AH}$ ) for other infection are excluded by this study.

UHC serves as a tertiary public center which deals with the treatment of acute cases and patients who have vital health problems. American Hospital with three hospitals private center offers a private service to patients with a wide range of treatments from the simplest to the most complicated. Many of the patients treated at UHCMTH, Tirana, and those treated at the $\mathrm{AH}$, had the necessity of their treatment with CRBSI. We analyzed all patients hospitalized near these two large diagnostic centers who were suspected as cases bloodstream infections caused by VCs.

In terms of record files information of each of patients with CRBSI regarding their individual data were obtained from database systems of two hospital centers that are included in this study. Sociodemographic data such as age and gender was requested. Furthermore, we were obtained data about the ward where they were hospitalized, the type of catheter used, and the problems they had encountered with these patients. Regarding the result of microbiological testing findings, the data for each patient is were obtained from the Laboratory of Microbiology at UHC and $\mathrm{AH}$. For positive cases, it is seen which pathogen caused this infection and if they performed the antimicrobial resistance. Statistical analysis for all data was performed using the Statistical Package for the Social Sciences version 20.0 (Chicago, IL, USA). Age, in the data analysis, was considered as continuous quantitative variable. Gender, in the data analysis, was considered as a binary variable (female/ male). Descriptive analyses were performed: Mean, frequency, and percentage are given for each data. Categorical variables were compared by the $\chi^{2}$ test or Fisher's exact test (if expected cell counts were <5) and continuous variables were compared by Student's $t$-test. The data were presented by tables and figures accompanied by the relevant explanation. Values $<0.05$ are considered statistically significant and logistic regression for odds ratio $95 \%$ confidence interval $(\mathrm{CI})$ is used to determine the relationship between risk factors and CRBIs.

\section{Results}

The prevalence of central VC-related blood infections for the 170 cases included in this study was $58.8 \%$ (100/170 cases). In Table 1, we have presented the baseline patient characteristics of suspected CRBSI cases for both laboratories (UHC and $\mathrm{AH}$ ) and positivity within each category of variables.

Table 1: Baseline patient characteristics and catheters profile among the suspected cases for CRBSI in UHC and AH

\begin{tabular}{llll}
\hline Variables & Total number of cases & Negative & Positive \\
\hline Hospital centers & 170 & 70 & 100 \\
$\quad$ UHC "Mother Theresa“ & $126(74.1 \%)$ & $44(34.9 \%)$ & $82(65.1 \%)$ \\
$\quad$ American Hospital & $44(25.9 \%)$ & $26(59.09 \%)$ & $18(40.91 \%)$ \\
Gender & & & \\
$\quad$ Female & $60(35.3 \%)$ & $23(38.4 \%)$ & $37(61.6 \%)$ \\
$\quad$ Male & $110(64.7 \%)$ & $47(42.7 \%)$ & $63(57.3 \%)$ \\
Age groups & $7(4.1 \%)$ & & \\
<30 years old & $21(12.3 \%)$ & $14(66.7 \%)$ & $2(28.6 \%)$ \\
$30-40$ years old & $26(15.3 \%)$ & $11(42.3 \%)$ & $15(57.3 \%)$ \\
41-50 years old & $42(24.7 \%)$ & $18(42.9 \%)$ & $24(57.1 \%)$ \\
$51-60$ years old & $51(30 \%)$ & $17(33.3 \%)$ & $34(66.7 \%)$ \\
61-70 years old & $23(13.5 \%)$ & $5(61.6 \%)$ & $18(21.7 \%)$ \\
$>71$ years old & & & \\
Catheters profile & $21(12.3 \%)$ & $11(52.4 \%)$ & $10(47.6 \%)$ \\
Femoral venous catheters & $42(24.7 \%)$ & $19(45.3 \%)$ & $23(54.7 \%)$ \\
Jugular venous catheters & $42 \%)$ \\
$\quad$ Subclavian central catheters & $29(17 \%)$ & $12(41.4 \%)$ & $17(58.6 \%)$ \\
Intravascular catheters & $25(14.7 \%)$ & $15(60 \%)$ & $10(40 \%)$ \\
$\quad$ Central venous catheters & $74(43.5 \%)$ & $24(32.4 \%)$ & $50(67.6 \%)$ \\
\hline
\end{tabular}

The positivity from the UHC "Mother Theresa" resulted $65.1 \%$ (82/126 cases) and the positivity from $\mathrm{AH}$ resulted $40.91 \%$ (18/44 cases). Patients from UHC Mother Theresa were (odds ratio) 2.69 times higher in risk for CRBSI compared to patients from $\mathrm{AH}$, for $\mathrm{Cl}$ $95 \%(1.33-5.44) \mathrm{p}$ value resulted to be with strong association $=0.005$.

Overall, 170 patient's female and male in our study, the positivity of CRBSI for female resulted $37 \%$ and $63 \%$, respectively. If we compared the positivity within each gender, female has the higher positivity versus male. Hence, the positivity resulted $61.6 \%$ (37/60) for female and $57.3 \%$ (63/110) for male. We did not found an association for the positivity and gender. $p$ value resulted $>0.05$. Patients $<30$ years old presented only $4.1 \%$ of all analyzed cases.

The most predominant age groups resulted patients $61-70$ years old and $51-60$ years old with $30 \%$ and $24.7 \%$, respectively. We have calculated the positivity within each category of age. As it shown in 
Table 1, the age groups $61-70$ years have the higher positivity $66.7 \%$. Related to the age groups, $41-50$ years old and 51-60 years old can be mention that they presented almost the same prevalence of positivity $57.7 \%$ and $57.1 \%$, respectively. The age groups more than 71 years old present the lowest positivity within the group. We have analyzed the types of catheters used for each patient that was introduced in this study. The most predominant type of catheters was central VCs in $43.5 \%$ of all analyzed cases. We have used the same calculated positivity for each of catheter types. The positivity within each type is as follows. Patients to whom a central VC has been applied had a higher positivity compared to other catheters types. Hence, the positivity of patients with CVS is $67.6 \%$ of cases, patients with subclavian central catheters are $58.6 \%$, patients with jugular VCs are $54.7 \%$, patients with femoral VCs are $47.6 \%$, and the last one is the patients with intravascular catheters with positivity $40 \%$. Figure 1 presents the distribution of positive and negative all catheters profile among our analyzed patients.

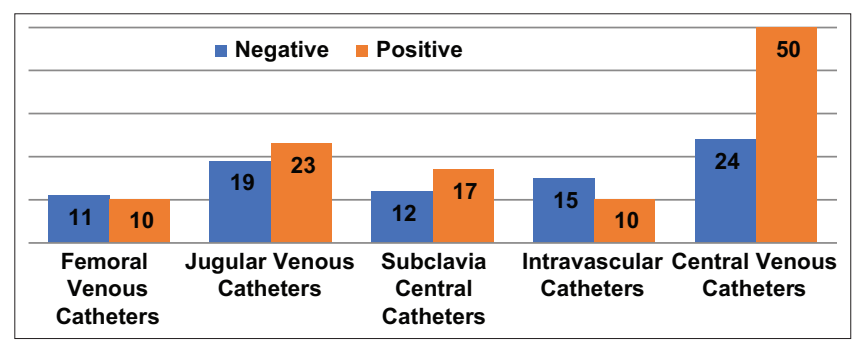

Figure 1: The number of negative/positive cases divided by catheter profile

Table 2 presents the types of bacteria that have been encountered in CRBSI-suspected patients for two hospital centers (UHC and AH). As Gramnegative bacteria, the species that were encountered in hospitalized patients at UHC are: Acinetobacterspp. in a total resulted $8.6 \%$ (Acinetobacter baumannii one case), Enterobacter spp. 1.2\%, Enterococcus faecium 1.2\% and Enterococcus faecalis 3.6\%, Klebsiella pneumoniae $1.2 \%$, Pantoea agglomerans $1.2 \%$, Proteus spp. $3.6 \%$ in total (Proteus mirabilis two cases), Pseudomonas aeruginosa $6.2 \%$, and Serratia odorifera $1.2 \%$. The genus Staphylococcus spp. (63.4\%) was identified as a Gram-positive bacterium and the most encountered species were Staphylococcus aureus, Staphylococcus epidermidis, Staphylococcus haemolyticus, etc.

Regarding the distribution of microorganisms in patients hospitalized at $\mathrm{AH}$, we found $A$. baumannii $16.6 \%$ and Pseudomonas spp. (11.1\%), the most common Gram-negative bacteria encountered in these patients, while other Gram-negative species such as P. mirabilis; Enterobacter spp.; and Cronobacter spp. resulted in 5.6\%, respectively. On the other hand, Grampositive bacteria resulted as below; Staphylococcus epidermidis $33.2 \%$; S. aureus $11.1 \%$; and Kocuria kristinae and $E$. faecalis in $5.6 \%$, respectively.
Table 2: Organisms isolated from catheter-related bloodstream infection (CRBSI)

\begin{tabular}{lll}
\hline Types of bacteria & $\mathrm{UHC}(\mathrm{n} / \%)$ & $\mathrm{AH}$ \\
\hline Total no. of Gram negative and Gram positive & $82 / 126$ & $18 / 44$ \\
Gram-negative bacteria & & \\
Acinetobacter spp. (Acinetobacter baumannii) & $7(8.6 \%)$ & $3(16.6 \%)$ \\
Enterobacter spp. & $1(1.2 \%)$ & $1(5.6 \%)$ \\
Klebsiella pneumoniae & $1(1.2 \%)$ & $0(0 \%)$ \\
Pantoea agglomerans & $1(1.2 \%)$ & $0(0 \%)$ \\
Proteus spp. (Proteus mirabilis) & $3(3.6 \%)$ & $1(5.6 \%)$ \\
Pseudomonas aeruginosa & $5(6.2 \%)$ & $2(11.1 \%)$ \\
Serratia odorifera & $1(1.2 \%)$ & $0(0 \%)$ \\
Cronobacter spp. & $0(0 \%)$ & $1(5.6 \%)$ \\
Gram-negative bacteria (without specification) & $6(7.3 \%)$ & \\
Gram-positive bacteria & & \\
Staphylococcus spp. & $18(22.0 \%)$ & $0(0 \%)$ \\
Staphylococcus lugdunensis & $1(1.2 \%)$ & $0(0 \%)$ \\
Staphylococcus aureus & $11(13.4 \%)$ & $2(11.1 \%)$ \\
Staphylococcus epidermidis & $18(22.0 \%)$ & $6(33.2 \%)$ \\
Staphylococcus haemolyticus & $4(4.9 \%)$ & $0(0 \%)$ \\
Enterococcus faecium & $1(1.2 \%)$ & $0(0 \%)$ \\
Enterococcus faecalis & $3(3.6 \%)$ & $1(5.6 \%)$ \\
Streptococcus spp. & $1(1.2 \%)$ & $0(0 \%)$ \\
Kocuria kristinae & $0(0 \%)$ & $1(5.6 \%)$ \\
\hline
\end{tabular}

All cases resulted as positive for CRBSI to the microbiological laboratory have undergone antimicrobial resistances test. The range of antibiotics used for each patient confirmed for the presence of bacteria is relatively high and ranges from 18 to 27 antibiotics for each. In Table 3, we have presented the susceptible, intermediate susceptibility, and resistant for each antibiotic used.

Table 3: Distribution of antimicrobial resistance for positive cases

\begin{tabular}{|c|c|c|c|c|}
\hline Antibiotics & Total number & Susceptible & Intermediate susceptibility & Resistant \\
\hline Doxycycline & 16 & 5 & 5 & 6 \\
\hline Cefixime & 13 & 2 & 1 & 10 \\
\hline Cefoxitin & 8 & 2 & & 6 \\
\hline Imipenem & 15 & 3 & 3 & 9 \\
\hline Clindamycin & 8 & 2 & & 6 \\
\hline Ceftazidime & 13 & 1 & 5 & 7 \\
\hline Ertapenem & 7 & 2 & & 5 \\
\hline Nalidixic acid & 17 & 2 & 2 & 13 \\
\hline Tobramycin & 12 & 3 & 1 & 8 \\
\hline Moxifloxacin & 18 & 11 & 7 & \\
\hline Meropenem & 17 & 4 & 4 & 9 \\
\hline Vancomycin & 15 & 2 & 7 & 6 \\
\hline Cefazolin & 11 & 3 & 1 & 7 \\
\hline Rifampicin & 18 & 10 & 4 & 4 \\
\hline Ofloxacin & 5 & 3 & & 2 \\
\hline Azithromycin & 14 & 1 & 1 & 12 \\
\hline Cefotaxime & 9 & 4 & & 5 \\
\hline Cefuroxime & 17 & 4 & 1 & 12 \\
\hline Amoxycillin & 15 & 2 & 2 & 11 \\
\hline Levofloxacin & 17 & 5 & 2 & 10 \\
\hline Ceftriaxone & 17 & 6 & & 11 \\
\hline Gentamycin & 18 & 8 & 2 & 8 \\
\hline Clarithromycin & 7 & 1 & 2 & 4 \\
\hline $\begin{array}{l}\text { Piperacillin/ } \\
\text { tazobactam }\end{array}$ & 16 & 5 & 3 & 8 \\
\hline Norfloxacin & 17 & 5 & 1 & 11 \\
\hline Cefepime & 10 & 3 & & 7 \\
\hline Ciprofloxacin & 16 & 5 & 2 & 9 \\
\hline Doripenem & 8 & 1 & 1 & 6 \\
\hline Amikacin & 7 & 2 & 4 & 1 \\
\hline Cefaclor & 5 & 1 & 1 & 3 \\
\hline Nitrofurantoin & 8 & 5 & 1 & 2 \\
\hline Amoxicillin & 1 & & & 1 \\
\hline Ticarcillin & 1 & & & 1 \\
\hline Bactrim & 2 & 1 & & 1 \\
\hline Ampicillin & 4 & 1 & & 3 \\
\hline Aztreonam & 1 & & 1 & \\
\hline Co-trimoxazole & 1 & 1 & & \\
\hline Colistin & 1 & & 1 & \\
\hline Cefpodoxime & 1 & & 1 & \\
\hline Ofloxacin & 1 & & & 1 \\
\hline Gatifloxacin & 1 & & & 1 \\
\hline Ticarcillin & 1 & & & 1 \\
\hline Novobiocin & 1 & 1 & & \\
\hline Cephalexin & 1 & 1 & & \\
\hline Augmentin & 1 & & & 1 \\
\hline Cefprozil & 1 & & & 1 \\
\hline Teicoplanin & 1 & 1 & & \\
\hline $\begin{array}{l}\text { Ticarcillin/ } \\
\text { clavulanic acid }\end{array}$ & 2 & 1 & 1 & \\
\hline
\end{tabular}




\section{Discussion}

VCs are the most commonly used medical devices in hospitalized patient's settings. They have become indispensable tools for the successful treatment of patients with chronic or life-threatening illnesses. The establishment of VCs provides a secure access to the central circulation for infusion of therapies, nutritional support, hemodynamic monitoring, hemodialysis, etc. Although the benefits we receive from using VCs, in most cases, the problems encountered by them outweigh the benefits gained, especially when a long-term approach to the central venous system is needed. VC patients pose a risk of developing local complications and systemic infectious complications. The most serious complications are bacteremia, sepsis, and mortality [7], [10], [11], [12]. The problem of circulatory infections related to the use of VCs has been gaining increasing attention in recent years [10]. This is because VCs cause a lot of morbidity and mortality, which increase the costs of health care [6], [13]. All over the world, diagnostic tests for CRBSI are recommended/ performed in those patients who are clinically suspected of having CRBSI (i.e., present with unspecified signs such as fever, hypotension, tremor, leukocytosis, and no other obvious focus of infection) [10].

The prevalence of catheter-related blood infections in 170 patients analyzed in this study during the periods 2016-2018, for public and private hospital center was $58.8 \%$. This prevalence is higher than other study conducted by Negi et al. (2019) who were the prevalence of CRBSI resulted $24.4 \%$, and Curtis (2009), the prevalence of CRBSI resulted $22.7 \%$. Nidhi et al. [14] and Curtis [15], but our prevalence was lower than another study conducted by Gahlot et al., 2013, were found in their study, the CRBSI prevalence was $62.5 \%$ [16]. We have analyzed data from two different hospitals which represent two different services public and private. In 126 patients admitted to UHC, $34.9 \%(44 / 126)$ tested negative and $65.1 \%(82 / 126)$ tested positive for CRBSI. Related to the hospitalized patients at the American Hospital (44 patients in total), the positivity for CRBSI resulted $40.9 \%$ (18/44) was positive and negative $59.1 \%$ (26/44). If we compare the positivity founded between the cases analyzed by UHC and those by $\mathrm{AH}$, it is clear that the number of patients and also the prevalence is higher for UHC. Hence, patients from UHC are 2.69 times more likely to have problems with catheter-induced infections compared to $\mathrm{AH}$ patients (odds ratio 2.69); $\mathrm{Cl} 95 \%$ (1.33-5.44) p value resulted in 0.005 .

The exact mechanisms by which gender may influence the risk for CRBSI infection are unclear, but may be related to changes in skin colonization or unknown anatomical differences between men and women. Findings regarding $\mathrm{CRBSI}$ are consistent throughout the literature [17], [18], [19], [20]. According to Bevin Cohen et al., no study has found significantly higher rates of infection in women if we compare them with men [21].

In our study, the positivity of CRBSI for female resulted $37 \%$ and for male $63 \%$. If we compared the positivity within each gender, female has the higher positivity versus male. Hence, the positivity resulted $61.6 \%(37 / 60)$ for female and $57.3 \%$ (63/110) for male. We did not find an association for the positivity and gender. The $p$ value resulted $>0.05$. Patients $<30$ years old presented only $4.1 \%$ of all analyzed cases.

Some studies were not found an association between the age and higher risk for bacteremia in VC types [22], [23], [24], [25] whereas other studies reported higher risk of hospitalized septicemia in older patients [26], [27]. Regarding our data, the mean age results $59.68 \pm 14.26$, with minimum age 9 years old and maximum age 83 years old. In this category of variables, we have calculated the positivity within each age group to seen which of them has the higher positivity. After the calculated of data, age groups 61-70 years have the higher positivity $66.7 \%$, and the age groups $41-50$ years old and 51-60 years old presented almost the same prevalence of positivity $57.7 \%$ and $57.1 \%$, respectively, meanwhile, the age groups more than 71 years old present the lowest positivity within the group.

All types of catheters are associated with catheter-related bloodstream infection (CRBSI). CVADs are associated with a higher rate of CRBSI than peripheral IV catheters, therefore, interventions to reduce the rate of $\mathrm{CRBSI}$ are especially important for their management and care [8]. Elsewhere CRBSI is also referred to as central line-associated bacteremia and catheter-related infection [28]. In our study, we found a strong significant correlation which was observed in terms of positivity and catheter placement location for $\chi^{2}=2.3 \mathrm{Cl} 95 \% \mathrm{p}=0.007$

Infections are thought to arise through contamination from commensal skin flora and may be introduced during insertion or subsequent care. The catheter insertion site itself provides the most direct route of entry for the pathogen and this is the most common cause of CRBSI. These infections are caused mainly by Gram-positive bacteria, in particular S. aureus and coagulase-negative staphylococci such as $S$. epidermidis, which is the most common [14]. However, infections can be caused by a wide range of microorganisms including Enterococci, Candida spp., Acinetobacter spp., Pseudomonas spp., and Klebsiella spp. It is likely that specific pathogens vary depending on different wards of hospitals and the individual colonization profile of the patient. In long-term catheters, the hub of the catheter is the main area for colonization and portal of infection and it is suggested that increasing length of catheterization is linked with a greater risk of developing a catheter-related infection [29], [30], [31]. 
Regarding the spectrum of bacteria implicated in CRBSI infections ( 100 positivity/170 patients in total) in both hospitalized patients (private and public), the most predominant bacteria resulted Gram positive in $67 \%$ (67/100) compared to Gram negative 33\% (33/100).

In UHC (82 positive cases), our study shows that most $69.5 \%(57 / 82)$ of the patients were caused by Gram-positive organisms as compared with 30.5\% (25/82) of those caused by Gram-negative organisms. Related to CRBSI infections in AH (18 positive cases), our study shows that most $55.5 \%(10 / 18)$ of the cases were caused by Gram-positive organisms as compared with $44.5 \%(8 / 18)$ of those caused by Gram-negative organisms.

In majority for both hospitals, bacteremia was caused from Gram-positive bacteria. In patients with CRBSIs, only $4(30.7 \%)$ out of 13 of the total S. aureus isolates were methicillin-resistant and $3(21.4 \%)$ out of $14 \mathrm{Gram}$-negative bacterial isolates were extendedspectrum beta-lactamase-producing organisms (such as Enterobacter spp.; K. pneumoniae; P. mirabilis; and $P$. aeruginosa). A total of $5(29.4 \%)$ out of 17 isolates were multidrug resistance including five isolates of Acinetobacter spp. and three isolates of $P$. aeruginosa.

Our study shows that Gram-positive bacteria were the most predominant compared to Gram-negative bacteria but regarding the antimicrobial resistance, the Gram-negative bacteria resulted majority of multidrug resistance.

Allsamplesthatwereanalyzed inmicrobiological laboratory of both hospitals (UHC and $\mathrm{AH}$ ), for the presence of infection, have undergone to antibiogram test after a positive result. A wide range of antibiotics [8], [19], [20], [21], [22], [23], [24], [25], [26], [27] were used for each patient that is confirmed for the presence of bacteria. Antibiotics such as moxifloxacin, rifampicin, and gentamycin show the highest susceptibility test in almost of positive cases, while other antibiotics such as doxycycline, cefixime, ceftazidime, nalidixic acid, tobramycin, and meropenem show the highest number of antimicrobial resistances.

\section{Conclusion}

The overall prevalence of CRBSI in our study was $58.8 \%$. Patients from Mother Theresa Hospital have the highest prevalence compared to patients of American Hospital. Men patients were the most predominant sex; age groups 61-70 years old presented the highest positive cases with CRBSI. Staphylococcus spp., Acinetobacter spp., Proteus spp., etc., were the most common isolate. Our study shows that Gram-positive bacteria were the most predominant compared to Gram-negative bacteria. We found antimicrobial resistance almost in all bacteria, but Gram-negative bacteria resulted majority of multidrug resistance. These complications are often related to the technique that the medical staff uses while performing the procedure. Furthermore, it is important to recognize and manage these complexities of immediate that may occur, because they can often become life threatening to the patient.

\section{Recommendation}

An early diagnosis of cases with CRBSI infection is recommended because this will avoid morbidity and mortality related to CRBSI.

The final diagnosis of catheter infection can be made using a combination of symptoms and clinical signs along with quantitative culture techniques.

Always should be taken care in determining a suspect case with CRBSI, because there is a salient difficulty among the medical staff to make distinguishing infection from contamination.

Infection of CRBSI is completely preventable if we apply strict hygiene measures, all medical staffs are training and a high standard individual care must be offer.

Sterile barrier precautions and skin asepsis reduce contamination from commensal organisms, and it is widely believed that routine change of catheters decreases colonization levels.

\section{References}

1. Hoefel A. Biofilm Formation in Central Venous Catheters a Prospective Study Performed with Catheters from Organ Donors, Diploma Thesis; 2016.

2. Ruesch S, Walder B, Tramèr MR. Complications of central venous catheters: Internal jugular versus subclavian access--a systematic review. Crit Care Med. 2002;30(2):454-60. https:// doi.org/10.1097/00003246-200202000-00031

PMid:11889329

3. YousifA, Jamal MA, Raad I. Biofilm-based central line-associated bloodstream infections. Adv Exp Med Biol. 2015;830:157-79. https://doi.org/10.1007/978-3-319-11038-7_10

PMid:25366227

4. Gow KW, Hickman RO. AAP experience. National Conference and Exhibit. What's in a Name. San Diego, USA: The History of Central Venous Catheters; 2014.

5. Marcos M, Soriano A, Iñurrieta A, Martínez JA, Romero A, Cobos $\mathrm{N}$, et al. Changing epidemiology of central venous catheter-related bloodstream infections: Increasing prevalence of Gram-negative pathogens. J Antimicrob Chemother. 2011;66(9):2119-25. https://doi.org/10.1093/jac/dkr231

PMid:21665905 
6. Raad I, Hanna H, Maki D. Intravascular catheter-related infections: Advances in diagnosis, prevention, and management. Lancet Infect Dis. 2007;7(10):645-57. https://doi.org/10.1016/ S1473-3099(07)70235-9

PMid:17897607

7. Mermel LA, Allon M, Bouza E, Craven DE, Flynn P, O‘Grady NP et al. Clinical practice guidelines for the diagnosis and management of intravascular catheter-related infection: 2009 update by the infectious Diseases Society of America. Clin Infect Dis. 2009;49(1):1-45.

PMid:19489710

8. Maki DG, Kluger DM, Crnich CJ. The risk of bloodstream infection in adults with different intravascular devices: A systematic review of 200 published prospective studies. Mayo Clin Proc. 2006;81(9):1159-71. https://doi.org/10.4065/81.9.1159 PMid:16970212

9. Sreeramoju PV, Tolentino J, Garcia-Houchins S, Weber SG. Predictive factors for the development of central line-associated bloodstream infection due to gram-negative bacteria in intensive care unit patients after surgery. Infect Control Hosp Epidemiol. 2008;29(1):51-6. https://doi.org/10.1086/524334 PMid:18171187

10. Patil HV, Patil VC, Ramteerthkar MN, Kulkarni RD. Central venous catheter related bloodstream infections in the intensive care unit. Indian J Crit Care Med. 2011;15(4): 213-23. https:// doi.org/10.4103/0972-5229.92074

PMid:22346032

11. Pronovost $P$, Needham D, Berenholtz S, Sinopoli D, Chu H, Cosgrove $\mathrm{S}$, et al. An intervention to decrease catheterrelated bloodstream infections in the ICU. $\mathrm{N}$ Engl $\mathrm{J}$ Med. 2006;355(26):2725-32. https://doi.org/10.1056/NEJMoa061115 PMid:17192537

12. Richet $H$, Hubert $B$, Nitemberg $G$, Andremont A, Buu-Hoi A, Ourbak $\mathrm{P}$, et al. Prospective multicenter study of vascularcatheter-related complications and risk factors for positive central catheter cultures in intensive care unit patients. J Clin Microbial. 1990;28(11):2520-5. https://doi.org/10.1128/ jcm.28.11.2520-2525.1990 PMid:2254429

13. Frasca D, Dahyot-Fizelier C, Mimoz O. Prevention of central venous catheter-related infection in the intensive care unit. Crit Care. 2010;14(2):212. https://doi.org/10.1186/cc8853 PMid:20236456

14. Nidhi N, Suchandra G, Iva C, Vijay K. Prevalence of central line associated blood stream infection (CRBSI) and catheter colonization in ICU settings of a tertiary care hospital in subHimalayan region. Trop J Pathol Microbiol. 2019;5(10):815-21.

15. Curtis RL. Catheter-related bloodstream infection in the intensive care unit. J Iran Chem Soc. 2009;10(2):102-8.

16. Gahlot R, Nigam C, Kumar V, Gupta M. Catheter related bloodstream infections in ICU: A study from North India. Int J Infection Control. 2013;9(2):4.

17. Al-Hasan MN, Lahr BD, Eckel-Passow JE, Baddour LM. Epidemiology and outcome of Klebsiella species bloodstream infection: A population-based study. Mayo Clin Proc. 2010;85:139-44. https://doi.org/10.4065/mcp.2009.0410 PMid:20118389

18. Al-Hasan MN, Lahr BD, Eckel-Passow JE, Baddour LM. Temporal trends in Enterobacter species bloodstream infection: A population-based study from 1998-2007. Clin Microbiol Infect. 2011;17:539-45. https://doi. org/10.1111/j.1469-0691.2010.03277.x

PMid:20518795

19. Garibaldi RA, Burke JP, Dickman ML, Smith CB. Factors predisposing to bacteriuria during indwelling urethral catheterization. N Engl J Med. 1974;291(5):215-9. https://doi. org/10.1056/NEJM197408012910501

PMid:4834750

20. Gokula RR, Hickner JA, Smith MA. Inappropriate use of urinary catheters in elderly patients at a midwestern community teaching hospital. Am J Infect Control. 2004;32(4):196-9. https:// doi.org/10.1016/j.ajic.2003.08.007

PMid:15175612

21. Cohen B, Choi YJ, Hyman S, Furuya EY, Neidell M, Larson E. Gender differences in risk of bloodstream and surgical site infections. J Gen Intern Med. 2013;28(10):1318-25. https://doi. org/10.1007/s11606-013-2421-5 PMid:23605308

22. Hoen B, Paul-Dauphin A, Hestin D, Kessler M. EPIBACDIAL A multicenter prospective study of risk factors for bacteremia in chronic hemodialysis patients. J Am Soc Nephrol. 1998;9(5):869-76. https://doi.org/10.1681/ASN.V95869 PMid:9596085

23. Tokars JI, Light P, Anderson J, Miller ER, Parrish J, Armistead N, et al. A prospective study of vascular access infections at seven outpatient hemodialysis centers. Am J Kidney Dis. 2001;37(6):1232-40. https://doi.org/10.1053/ajkd.2001.24527 PMid:11382693

24. Taylor G, Gravel D, Johnston L, Embil J, Holton D, Paton S, et al. Incidence of bloodstream infection in multicenter inception cohorts of hemodialysis patients. Am J Infect Control. 2004;32(3):155-60. https://doi.org/10.1016/j.ajic.2003.05.007 PMid:15153927

25. Sedlacek M, Gemery JM, Cheung AL, Bayer AS, Remillard BD. Aspirin treatment is associated with a significantly decreased risk of Staphylococcus aureus bacteremia in hemodialysis patients with tunneled catheters. Am J Kidney Dis. 2007;49(3):401-8. https://doi.org/10.1053/j.ajkd.2006.12.014

PMid:17336701

26. Powe NR, Jaar B, Furth SL, Hermann J, Briggs W. Septicemia in dialysis patients: Incidence, risk factors, and prognosis. Kidney Int. 1999;55:1081-90. https://doi. org/10.1046/j.1523-1755.1999.0550031081.x

PMid:10027947

27. Murea M, James KM, Russell GB, Byrum GV $3^{\text {rd }}$, Yates JE, Tuttle NS, et al. Risk of catheter-related bloodstream infection in elderly patients on hemodialysis. Clin J Am Soc Nephrol. 2014;9(4):764-70. https://doi.org/10.2215/CJN.07710713 PMid:24651074

28. Culverwell E. Central Venous Access Devices. Resource Book. $1^{\text {st }}$ ed. Professional Development Unit; 2011.

29. Orsini J, Mainardi C, Muzylo E, Karki N, Cohen N, Sakoulas G. Microbiological profile of organisms causing bloodstream infection in critically ill patients. J Clin Med Res. 2012;4(6):371-7. https://doi.org/10.4021/jocmr1099w PMid:23226169

30. Hasan S, Imtiaz F, Khan MA, Iqbal A. Blood stream infections and their sensitivity pattern in a tertiary care hospital. Ther Adv Infect Dis. 2015;2(52):2321-3485.

31. Gaynes R. Definitions and Epidemiology of Nosocomial Intravascular Catheter-related (Primary) Bloodstream Infections; 2009. 